\title{
Effectiveness of Rituximab in Patients with Rheumatoid Arthritis: Observational Study from the British Society for Rheumatology Biologics Register
}

MOETAZA M. SOLIMAN, KIMME L. HYRICH, MARK LUNT, KATH D. WATSON, DEBORAH P.M. SYMMONS, and DARREN M. ASHCROFT, and the British Society for Rheumatology Biologics Register

\begin{abstract}
Objective. To assess the effectiveness of rituximab (RTX) in patients with rheumatoid arthritis (RA) in routine clinical practice, and to identify predictors of 6-month response to RTX in patients for whom at least 1 anti-tumor necrosis factor- $\alpha$ (anti-TNF) therapy has failed.

Method. The analysis involved 646 patients with RA registered with the British Society for Rheumatology Biologics Register (BSRBR) who were starting RTX and were followed for at least 6 months. Change in the 28-joint Disease Activity Score (DAS28), European League Against Rheumatism (EULAR) response, and proportions of patients achieving disease remission were used to assess the clinical response 6 months after starting RTX. Regression analyses were used to identify factors associated with the response in the patients for whom anti-TNF therapy had not worked. The models included baseline demographics, disease characteristics, baseline Health Assessment Questionnaire (HAQ), and drug history including biologic history.

Results. The mean DAS28 at baseline was 6.2 (95\% CI 6.1, 6.3), which decreased significantly to 4.8 (95\% CI $4.7,4.9)$ at the 6-month followup. Seventeen percent of the patients were EULAR good responders and $43 \%$ were moderate responders. Eight percent of the patients achieved disease remission. Subjects with higher baseline DAS28 score and those with positive rheumatoid factor (RF) status were significantly associated with a decrease in their DAS28 score (improvement), while women and patients with higher baseline HAQ score were less likely to improve.

Conclusion. RTX has proven to be effective in routine clinical practice. When anti-TNF therapy fails, response to RTX was influenced by baseline DAS28 score, RF status, baseline HAQ score, and sex. (First Release Dec 15 2011; J Rheumatol 2012;39:240-6; doi:10.3899/jrheum.110610)
\end{abstract}

Key Indexing Terms:

RHEUMATOID ARTHRITIS

PREDICTORS

EFFECTIVENESS
RITUXIMAB EULAR RESPONSE 28-JOINT DISEASE ACTIVITY SCORE
From the School of Pharmacy and Pharmaceutical Sciences, and the Arthritis Research UK Epidemiology Unit, University of Manchester, Manchester, United Kingdom.

Funding for the British Society for Rheumatology (BSR) Biologics Register was provided by the BSR. Prof. Symmons and Dr. Hyrich are principal investigators on the BSRBR. The BSR receives restricted income from UK pharmaceutical companies, currently Abbott Laboratories, Amgen, Roche, Schering Plough, and Wyeth Pharmaceuticals. This income finances a wholly separate contract between the BSR and the University of Manchester, which provides and runs the BSRBR data collection, management, and analysis services. The PhD work of Mrs. Soliman was supported by the Egyptian government.

M.M. Soliman, MSc, PhD Student, School of Pharmacy and Pharmaceutical Sciences, University of Manchester; K.L. Hyrich, MD, $P h D, F R C P C$, Senior Lecturer in Rheumatic Disease Epidemiology; M. Lunt, PhD, Senior Lecturer in Medical Statistics; K.D. Watson, PhD, Manager of Pharmacovigilance Studies; D.P.M. Symmons, MD, FFPH, FRCP, Professor of Rheumatology and Musculoskeletal Epidemiology, Arthritis Research UK Epidemiology Unit, University of Manchester; D.M. Ashcroft, BPharm, MSc, PhD, Professor of Pharmacoepidemiology, School of Pharmacy and Pharmaceutical Sciences, University of Manchester.

Address correspondence to Prof. D.M. Ashcroft, School of Pharmacy and Pharmaceutical Sciences, Stopford Building, University of Manchester, Oxford Road, Manchester M13 9PT, UK.

E-mail: darren.ashcroft@manchester.ac.uk

Full Release Article. For details see Reprints/Permissions at jrheum.org Accepted for publication September 28, 2011.
Rituximab (RTX) in combination with methotrexate (MTX) is licensed for the management of severe active rheumatoid arthritis (RA) in patients whose disease has not responded to nonbiological disease-modifying antirheumatic drugs (nbDMARD) and 1 or more anti-tumor necrosis factor- $\alpha$ (anti-TNF) therapies ${ }^{1,2}$. Randomized clinical trials (RCT) have shown the efficacy of RTX in improving the clinical symptoms of RA as measured by the American College of Rheumatology (ACR), the 28-joint Disease Activity Score (DAS28), and European League Against Rheumatism (EULAR) response criteria ${ }^{3,4,5}$. However, each of these studies examined efficacy in different populations of patients; for instance, patients who were rheumatoid factor (RF)-positive and had failed nbDMARD ${ }^{4}$, while the REFLEX trial ${ }^{3}$ included patients with RA who had failed anti-TNF. Recent RCT have also examined the efficacy after retreatment with a second course of RTX and the efficacy of different dose regimens ${ }^{6,7,8}$, some of which are limited to biological-naive patients $6,7,9$.

To date, few observational studies have reported on the effectiveness of RTX in anti-TNF-naive patients ${ }^{10,11,12}$ Several observational studies have reported on the effective-

Personal non-commercial use only. The Journal of Rheumatology Copyright $@$ C 2012. All rights reserved. 
ness of RTX in cases in which anti-TNF therapies have failed $^{13,14,15}$, while others reported on the effectiveness of RTX in a mixed population of anti-TNF-naive patients and failures $^{16,17,18,19}$. However, all these observational studies included relatively small numbers of patients (range from 10 to 103). A recent large observational study that pooled data from multiple registries in Europe has reported on the effectiveness of RTX in patients with $\mathrm{RA}^{20}$.

A study of 110 patients (32 anti-TNF-naive and 78 anti-TNF failures) reported that patients with positive RF, lower baseline Health Assessment Questionnaire (HAQ) score, or those who had failed fewer anti-TNF agents were more likely to achieve an $\mathrm{ACR} \geq 50$ response $^{21}$. In the same study, only RF positivity was found to be associated with a better EULAR response. Another recent study of 103 patients (40 anti-TNF-naive and 63 anti-TNF failures) identified high DAS28 and concomitant use of nbDMARD as predictors of response to first course of RTX in univariate logistic regression $^{11}$. A recent study using pooled data from multiple registries has identified predictors of good EULAR response ${ }^{20}$. However, there are no other data in the literature that address the predictors of response to a first course of RTX.

Using data from a national prospective cohort study in the United Kingdom, our current study aimed (1) to assess the effectiveness of RTX in patients with RA who were treated during routine clinical practice in the United Kingdom by evaluating treatment response 6 months after starting RTX; and (2) to identify baseline factors that are associated with better response in patients who had failed at least 1 anti-TNF therapy.

\section{MATERIALS AND METHODS}

Patient population. Patients registered with the British Society for Rheumatology Biologics Register (BSRBR) were used ${ }^{22}$. The BSRBR is a prospective observational cohort study that has recruited patients receiving biologic therapies for the management of RA in the United Kingdom. To be eligible for recruitment, patients had to be age 16 years or older and have started RTX not more than 6 months prior to registration. Registration for RTX was open to patients who were already participating in the study (because they were receiving anti-TNF therapy) or to those who had not been previously registered with the BSRBR. RTX was administered according to the licensed dose (two 1000-mg infusions taken 2 weeks apart).

Ethical approval for recruitment of patients to the BSRBR was granted by the North West Multicentre Research Ethics Committee. All patients provided written informed consent at the time of study registration, including those who were already registered with the BSRBR.

Baseline data. At the start of RTX treatment, baseline data were collected using different forms according to the type of registration. For patients who were new to the BSRBR, the consultant responsible for care was asked to complete (1) a consultant baseline questionnaire that collected data on the patient's demographic characteristics, DAS28 (at the time RTX was started), comorbidities, previous and current DMARD therapies, RF status, and smoking status; and (2) a prior biologic exposure form that collected data on the previous biological therapies and the reason for discontinuation (inefficacy, remission, adverse events, or other reasons). For patients who were already registered with the BSRBR and then switched to RTX, the consultant was asked to complete a BSRBR Short Baseline Form that collected data on DAS28 at the time RTX was started, current drug therapy, and comorbidities.
The other patient demographic characteristics were recalled from the original consultant baseline form, which was completed when the patient was first registered with the BSRBR for anti-TNF treatment. The previous biologics received and the reasons for discontinuation were obtained from the followup forms that were collected while registered for anti-TNF therapy. All the patients were asked to complete a baseline European Quality of Life 5 Dimensions (EQ5D) form ${ }^{23}$ and the HAQ, adapted for use in a UK population ${ }^{24}$.

Followup. Six months after starting RTX, the consultant completed followup questionnaires that collected data on the DAS28.

Data analysis. BSRBR data up to December 2010 were used in the current analysis. All patients with RA who started RTX and were registered with the BSRBR for RTX treatment were eligible for inclusion. The analysis was limited to patients for whom the 6 months' consultant followup was returned, with a recorded DAS28 score.

Six months' treatment effectiveness was assessed by (1) the change in DAS28 ${ }^{25}$ (baseline DAS28 to 6-month DAS28); (2) nonresponse, moderate, and good response according to the EULAR response criteria ${ }^{26}$; and (3) the proportion of patients achieving disease remission (DAS28 $<2.6$ ), according to the EULAR criteria ${ }^{27}$.

The mean change in DAS28 was compared between RF-negative and RF-positive patients and anti-TNF-naive patients versus anti-TNF failures using the t-test of 2 independent samples. The mean change in DAS28 was also compared between patients receiving RTX in combination with MTX, in combination with other nbDMARD, or with no nbDMARD, using one-way ANOVA. The EULAR response and remission rates were compared between the different subgroups of patients using Pearson chi-squared tests.

Multivariate regression models were used to identify factors associated with 6-months' response to RTX. Linear regression models were used to identify factors associated with change in DAS28. Logistic regression models were used to identify factors associated with achieving disease remission. Given that the biological history of the patient may influence the response to RTX, all regression models were limited to cases of anti-TNF failure $(n=540)$.

Covariates included (1) baseline demographics [age (decades), sex, presence of comorbidities (yes/no)]; (2) baseline disease characteristics [disease duration (decades), RF positivity (yes/no), DAS28]; (3) baseline physical function [HAQ score (0.1 unit)]; (4) concurrent therapy [steroids, nbDMARD (none/MTX/other)]; and (5) drug history [previous steroid (yes/no), number of the previous nbDMARD ( 3 or fewer/ 4 or more), number of the previous anti-TNF therapies (one/more than one), type of the most recently stopped anti-TNF therapy (receptor antagonist vs monoclonal antibody), and whether the reason for stopping the last anti-TNF therapy was due to inefficacy (yes/no)].

Forward stepwise selection method was used to select the variables that go into the multivariate models based on a significance level of 0.05 .

Further regression modeling was used to compare the response between anti-TNF-naive patients versus anti-TNF failures. The model was adjusted for propensity scores ${ }^{28}$ that were calculated using a logistic regression model that included any differences in baseline characteristics between the 2 subgroups of patients, any interaction between baseline variables, and any predictors of the outcome.

The results are presented as coefficient $(95 \% \mathrm{CI})$ for the linear regression models or as OR $(95 \% \mathrm{CI})$ for logistic models. Stata 10.1 software was used for all statistical analyses (Stata Corp., College Station, TX, USA).

\section{RESULTS}

Baseline characteristics. By December 2010, 646 patients registered with the BSRBR met the inclusion criteria for our current study. Of these, $83.6 \%(\mathrm{n}=540)$ had experienced anti-TNF failure and $16.4 \%(\mathrm{n}=106)$ were anti-TNF-naive patients. The baseline characteristics of the patients are presented in Table 1. The mean age was 58.7 (SD 11.6) years. Women made up $69.9 \%$ of the patients. RF-positive patients

Personal non-commercial use only. The Journal of Rheumatology Copyright $@$ C 2012. All rights reserved. 
Table 1. Baseline characteristics of patients receiving rituximab therapy. Values are mean \pm SD unless otherwise specified. Disease duration was available for $98 \%$ of the patients, RF status for 97\%, EQ5D for 93\%, HAQ for $90 \%$, ESR for $85 \%$, and C-reactive protein (CRP) for $54 \%$.

\begin{tabular}{|c|c|c|c|c|}
\hline Characteristics & $\begin{array}{l}\text { All RTX Patients, } \\
\qquad n=646\end{array}$ & $\begin{array}{c}\text { Patients who } \\
\text { Experienced } \\
\text { Anti-TNF Failure, } \\
\quad \mathrm{n}=540\end{array}$ & $\begin{array}{l}\text { Anti-TNF-naive } \\
\text { patients, } \\
n=106\end{array}$ & $\mathrm{p}^{\dagger}$ \\
\hline \multicolumn{5}{|l|}{ Demographics } \\
\hline Age, yrs & $58.7 \pm 11.6$ & $58.1 \pm 11.6$ & $61.6 \pm 11.7$ & 0.01 \\
\hline Women, n (\%) & $497(76.9)$ & $427(79.1)$ & $70(66.0)$ & 0.01 \\
\hline Current smoker, n (\%) & $136(21.1)$ & $114(21.1)$ & $22(20.8)$ & 0.93 \\
\hline Comorbidities*, n (\%) & $460(71.2)$ & $376(69.6)$ & $84(79.3)$ & 0.05 \\
\hline \multicolumn{5}{|l|}{ Disease characteristics } \\
\hline Disease duration, yrs & $14.3 \pm 10.1$ & $14.8 \pm 9.9$ & $11.8 \pm 10.6$ & 0.01 \\
\hline RF-positive, n (\%) & $424(65.6)$ & $346(64.1)$ & 78 (73.6) & 0.15 \\
\hline Swollen joint count & $8.9 \pm 5.8$ & $8.9 \pm 5.9$ & $8.9 \pm 5.3$ & 1.00 \\
\hline Tender joint count & $14.3 \pm 7.8$ & $14.3 \pm 7.8$ & $14.2+7.9$ & 0.92 \\
\hline Global health VAS & $70.0 \pm 20.2$ & $70.1 \pm 20.5$ & $69.6 \pm 18.6$ & 0.83 \\
\hline $\mathrm{CRP}, \mathrm{mg} / \mathrm{dl}$ & $34.2 \pm 38.0$ & $33.7 \pm 38.8$ & $36.6 \pm 33.2$ & 0.64 \\
\hline $\mathrm{ESR}, \mathrm{mm} / \mathrm{h}$ & $44.6 \pm 29.9$ & $44.4 \pm 30.3$ & $45.8 \pm 28.0$ & 0.70 \\
\hline DAS28 & $6.2 \pm 1.1$ & $6.2 \pm 1.2$ & $6.2 \pm 1.0$ & 0.91 \\
\hline \multicolumn{5}{|c|}{ Quality of life and physical function } \\
\hline EQ5D VAS & $45.9 \pm 22.6$ & $45.8 \pm 22.6$ & $46.8 \pm 22.3$ & 0.66 \\
\hline EQ5D utility score & $0.3 \pm 0.3$ & $0.3 \pm 0.3$ & $0.3 \pm 0.3$ & 0.60 \\
\hline HAQ & $2.0 \pm 0.6$ & $2.0 \pm 0.6$ & $1.9 \pm 0.6$ & 0.21 \\
\hline \multicolumn{5}{|c|}{ Current and previous drug use } \\
\hline No. previous nbDMARD & $4.2 \pm 1.8$ & $4.3 \pm 1.8$ & $3.6 \pm 1.4$ & 0.0001 \\
\hline \multicolumn{5}{|l|}{ Current nbDMARD, n (\%) } \\
\hline None & $143(22.1)$ & $108(20.0)$ & $35(33.0)$ & $<0.001$ \\
\hline MTX & $343(53.1)$ & $316(58.5)$ & $27(25.5)$ & \\
\hline Other & $160(24.8)$ & $116(21.5)$ & $44(41.5)$ & \\
\hline Pervious steroids, n (\%) & $485(75.1)$ & $407(75.4)$ & $78(73.6)$ & 0.70 \\
\hline Current steroids, n (\%) & $300(46.4)$ & $250(46.3)$ & $50(47.2)$ & 0.87 \\
\hline
\end{tabular}

* Comorbidities include angina, hypertension, stroke, epilepsy, myocardial infarction, asthma, chronic obstructive pulmonary disease, liver disease, renal disorder, peptic ulcers, diabetes, demyelination, hyperthyroidism, depression, or a history of tuberculosis or cancer. ${ }^{\dagger} \mathrm{P}$ value tests for significant differences between the cases in which anti-TNF therapy failed and anti-TNF-naive patients ( 2 independent samples, t-test for continuous variables, and Pearson chi-square test for categorical variables). RF: rheumatoid factor; TNF: tumor necrosis factor; RTX: rituximab; MTX: methotrexate; nbDMARD: nonbiological disease-modifying antirheumatic drugs; EQ5D: European Quality of Life 5 Dimensions; ESR: erythrocyte sedimentation rate; HAQ: Health Assessment Questionnaire; DAS28: 28-joint Disease Activity Score; VAS: visual analog scale.

were $65.6 \%$, and $71.2 \%$ had at least 1 comorbidity. As for RTX involvement, $22.1 \%$ of the patients were receiving RTX as a monotherapy, $53.1 \%$ received RTX in combination with MTX, and $24.8 \%$ in combination with other nbDMARD. The mean baseline DAS28 was 6.2 (SD 1.1) and the mean baseline HAQ score was 2.0 (SD 0.6).

For the anti-TNF failures, $57.4 \%$ had failed 1 anti-TNF drug while $33.7 \%$ had failed 2 of them (Table 2). The most recently stopped anti-TNF drug was etanercept in $43.0 \%$ of the patients, adalimumab in $38.0 \%$, and infliximab in $14.4 \%$. The reason for stopping the last anti-TNF drug was inefficacy in $43.2 \%$ of the patients.

Significant differences in baseline characteristics were found between cases of anti-TNF failure and anti-TNF-naive patients. Anti-TNF-naive patients were generally older and with shorter disease duration. They also tended to be men, to have tried fewer nbDMARD, to have more comorbidities, and to be receiving RTX more commonly in combination with other nbDMARD rather than with MTX.

Treatment response. Six months after starting RTX, the mean change in DAS28 was $-1.42(95 \%$ CI $-1.53,-1.30)$ in the entire cohort. According to the EULAR criteria, $17.2 \%$ of the patients were good responders and $43.2 \%$ were moderate responders (Table 3). Disease remission was achieved by $8.1 \%$ of patients.

There were no significant differences in change in DAS28, EULAR response, and disease remission rates between RF-positive and RF-negative patients $(\mathrm{p}=0.09,0.20$, and 0.38 , respectively). The changes in DAS28, EULAR response, and disease remission rates were also similar in patients receiving RTX as a monotherapy, in combination with MTX, or in combination with other nbDMARD ( $\mathrm{p}=0.86,0.82$, and 0.37 , respectively).

Personal non-commercial use only. The Journal of Rheumatology Copyright $@$ C 2012. All rights reserved. 
Predictors of treatment response at 6 months in anti-TNF failures. In multivariate analysis limited to patients who had experienced anti-TNF therapy failure, greater improvements in DAS28 were seen in patients with higher baseline DAS28 [coefficient $0.57(95 \% \mathrm{CI}-0.69,-0.46)$ per unit DAS28] and in patients positive for RF $[-0.30(95 \% \mathrm{CI}-0.58,-0.03)]$. However, higher HAQ scores $[0.29$ (95\% CI 0.06, 0.52)] and female sex $[0.45(95 \%$ CI $0.12,0.78)]$ were associated with

Table 2. Baseline biological drug history in cases of anti-TNF failure. All data are $\mathrm{n}(\%)$.

\begin{tabular}{lc}
\hline History & Patients, $\mathrm{n}=540$ \\
\hline Ever had etanercept & $238(44.1)$ \\
Ever had infliximab & $138(25.6)$ \\
Ever had adalimumab & $218(40.4)$ \\
No. previous anti-TNF therapies & \\
1 & $310(57.4)$ \\
2 & $182(33.7)$ \\
3 & $21(3.9)$ \\
Not recorded & $27(5.0)$ \\
Most recently stopped anti-TNF drug & \\
Etanercept & $232(43.0)$ \\
Infliximab & $78(14.4)$ \\
Adalimumab & $205(38.0)$ \\
Not recorded & $25(4.6)$ \\
Reason for stopping last biological therapy & \\
Inefficacy & $233(43.1)$ \\
Adverse events & $117(21.7)$ \\
Other & $42(7.8)$ \\
Not recorded & $148(27.4)$ \\
\hline
\end{tabular}

TNF: tumor necrosis factor. lesser improvement. Only older age (OR $0.72,95 \%$ CI 0.53 , 0.97 ) and baseline HAQ (OR $0.87,95 \%$ CI $0.83,0.92$ per unit HAQ) were significantly associated with lower odds of disease remission. Of the 21 patients who failed all of the 3 anti-TNF therapies, none achieved disease remission.

Cases of anti-TNF failure versus anti-TNF-naive patients. The mean change in DAS28 was significantly better in anti-TNF-naive patients $[-1.71(95 \% \mathrm{CI}-1.98,-1.44)]$ than in anti-TNF failures $[-1.36(95 \% \mathrm{CI}-1.49,-1.23) ; \mathrm{p}=0.03$; difference of 0.36 (95\% CI 0.04, 0.67); Table 3]. Anti-TNF-naive patients also showed better EULAR response rates compared to patients who had experienced anti-TNF failure $(\mathrm{p}=0.06)$. Disease remission was also more likely to be achieved in the anti-TNF-naive patients (14.2\%) compared to cases of anti-TNF failure $(6.9 \% ; \mathrm{p}=0.01)$. However, after adjustment for propensity scores, no significant differences in the change in DAS28 $(-0.20,95 \%$ CI $-0.54,0.13)$ or proportion achieving disease remission (OR 1.35, 95\% CI 0.60, 3.06) were found between anti-TNF-naive and cases of anti-TNF failure. The propensity score logistic model included age, disease duration, sex, comorbidities, number of previous nbDMARD, concurrent nbDMARD, RF status, baseline DAS28, baseline HAQ score, interaction between baseline HAQ and disease duration, and interaction between baseline HAQ and sex.

\section{DISCUSSION}

In our observational study, we evaluated the clinical effectiveness of RTX in patients with RA 6 months after starting treatment, in routine clinical practice in the United Kingdom. In agreement with the results of the published clinical trials, we found that RTX is an effective treatment for patients with

Table 3. Response to rituximab 6 months after starting treatment

\begin{tabular}{|c|c|c|c|c|c|c|c|c|c|c|c|}
\hline Outcome & $\begin{array}{c}\text { Entire } \\
\text { Cohort, } \\
\mathrm{n}=646\end{array}$ & $\begin{array}{c}\text { Cases of } \\
\text { Anti-TNF } \\
\text { Failure, } \\
\mathrm{n}=540\end{array}$ & $\begin{array}{l}\text { Anti-TNF- } \\
\text { naive } \\
\text { Patients, } \\
\mathrm{n}=106\end{array}$ & $\mathrm{p}^{\dagger}$ & $\begin{array}{c}\text { RF-positive, } \\
n=424\end{array}$ & $\begin{array}{c}\text { RF-negative, } \\
n=203\end{array}$ & $\mathrm{p}^{\dagger \dagger}$ & $\begin{array}{l}\text { RTX + MTX } \\
\quad \mathrm{n}=343\end{array}$ & $\begin{array}{c}\text { RTX } \\
\text { Monotherapy, } \\
n=143\end{array}$ & $\begin{array}{c}\text { RTX + Other } \\
\text { nbDMARD, } \\
\text { n }=160\end{array}$ & $\mathrm{p}^{\#}$ \\
\hline $\begin{array}{l}\text { Mean change } \\
\text { in DAS28 } \\
(95 \% \mathrm{CI})\end{array}$ & $\begin{array}{l}-1.42 \\
(-1.53 \\
-1.30)\end{array}$ & $\begin{array}{l}-1.36 \\
(-1.49 \\
-1.23)\end{array}$ & $\begin{array}{l}-1.71 \\
(-1.98 \\
-1.44)\end{array}$ & $0.03 *$ & $\begin{array}{l}-1.49 \\
(-1.63 \\
-1.34)\end{array}$ & $\begin{array}{l}-1.27 \\
(-1.46 \\
-1.07)\end{array}$ & $0.09 *$ & $\begin{array}{l}-1.43 \\
(-1.59 \\
-1.28)\end{array}$ & $\begin{array}{l}-1.43 \\
(-1.69 \\
-1.18)\end{array}$ & $\begin{array}{l}-1.36 \\
(-1.60 \\
-1.12)\end{array}$ & $0.86^{* *}$ \\
\hline Moderate & $\begin{array}{c}279 \\
(43.19)\end{array}$ & $\begin{array}{c}229 \\
(42.41)\end{array}$ & $\begin{array}{c}50 \\
(47.17)\end{array}$ & $0.06^{* * *}$ & $\begin{array}{c}187 \\
(44.10)\end{array}$ & $\begin{array}{c}85 \\
(41.87)\end{array}$ & $0.20 * * *$ & $\begin{array}{c}148 \\
(43.15)\end{array}$ & $\begin{array}{c}65 \\
(45.45)\end{array}$ & $\begin{array}{c}66 \\
(41.25)\end{array}$ & $0.82 * * *$ \\
\hline None & $\begin{array}{c}256 \\
(39.63)\end{array}$ & $\begin{array}{c}224 \\
(41.48)\end{array}$ & $\begin{array}{c}32 \\
(30.19)\end{array}$ & & $\begin{array}{c}160 \\
(37.74)\end{array}$ & $\begin{array}{c}90 \\
(44.33)\end{array}$ & & $\begin{array}{c}133 \\
(38.77)\end{array}$ & $\begin{array}{c}58 \\
(40.56)\end{array}$ & $\begin{array}{c}65 \\
(40.63)\end{array}$ & \\
\hline \multicolumn{12}{|c|}{ Achieving disease remission, $\mathrm{n}(\%)$} \\
\hline
\end{tabular}

$\dagger$ Test of significance between cases of anti-TNF failure and anti-TNF-naive patients. †† Between RF-negative and RF-positive patients. ${ }^{\#}$ Among patients with different concurrent nbDMARD. * Two independent samples, t-test. ** One-way ANOVA. *** Pearson chi-squared test. TNF: tumor necrosis factor; RF: rheumatoid factor; RTX: rituximab; MTX: methotrexate; nbDMARD: nonbiological disease-modifying antirheumatic drugs; EULAR: European League Against Rheumatism; DAS28: 28-joint Disease Activity Score.

Personal non-commercial use only. The Journal of Rheumatology Copyright @ 2012 . All rights reserved 
RA. Six months after starting RTX, the mean DAS28 scores significantly decreased (signifying improvement) by 1.42 $(95 \%$ CI $1.53,1.30)$ units. The decrease in disease activity was seen both in cases of anti-TNF failure and in anti-TNF-naive patients. Sixty percent of the patients were EULAR responders (moderate or good). However, only 17\% of the patients were good EULAR responders and only $8.1 \%$ of the patients achieved disease remission.

The response to RTX among the cases of anti-TNF failure was comparable to the results of a small observational study $(\mathrm{n}=20)$ that reported a 6-month EULAR response of $60 \%{ }^{15}$ (our results: 58.5\%). However, the response in the REFLEX trial was slightly higher $(65 \%)^{3}$. The higher mean baseline disease activity of patients in the REFLEX trial $(6.9 \pm 1.0 \mathrm{vs}$ $6.2 \pm 1.2$ in our cohort) may explain that trial's higher response rates. In general, comparing the response of the current analysis with the response reported in clinical trials might be inappropriate, because of the different populations included in those trials with different baseline characteristics, especially in those characteristics that have been found to predict response.

After adjustment for propensity scores, the response to RTX in the cases of anti-TNF failure versus anti-TNF-naive patients was similar. The unadjusted differences in response in anti-TNF-naive patients may occur because the cases of anti-TNF failure had longer disease duration and had failed a larger number of previous nbDMARD, suggesting more-resistant disease. To date, no RCT have compared the response in cases of anti-TNF failure versus anti-TNF-naive patients. However, one small observational study compared the response of these 2 populations $(n=20)$ and observed no significant difference in response as measured by change in DAS28 (1.8 vs 1.4). However, those patients were receiving RTX as monotherapy ${ }^{19}$. Another recent study of 40 anti-TNF-naive patients and 63 cases of anti-TNF failure showed similar responses in univariate analysis $(\mathrm{p}=0.118)^{11}$. Similar responses were also reported in a study of 14 TNF-naive patients and 81 cases of anti-TNF failure $(\mathrm{p}=1)^{12}$.

Patients receiving MTX with RTX showed a similar response to those receiving RTX as monotherapy or with other nbDMARD. These findings agree with the RCT of Edwards, et $a l^{4}$. Similar findings were reported in a retrospective observational study of 57 patients ${ }^{17}$. A recent retrospective study of 95 patients also reported similar EULAR response in patients treated with RTX + MTX and those treated with RTX alone ${ }^{12}$. Given that sustained benefits over 2 years of followup were shown only in RTX + MTX therapy rather than RTX monotherapy ${ }^{29}$, further observational studies are needed to confirm whether patients receiving RTX monotherapy will experience sustainability of response after successive treatments.

RF-positive status was found to be a significant predictor of the decrease in disease activity $(-0.30,95 \%$ CI -0.58 , -0.03 ) but this was not found to translate into either a moder- ate or a good EULAR response. This may be explained by the low coefficient (0.30) of the decrease in DAS28, which is $<0.6$, and so was translated to non-EULAR response. RTX acts by depleting B cells, which are believed to be the source of RF; therefore RTX may not act in RF-negative patients, and this may be why the first RCT of RTX included only RF-positive patients ${ }^{4}$. However, subsequent trials showed that RTX can work in both RF-negative and RF-positive patients ${ }^{3,5}$, and that was the case in our cohort of patients.

In one study, RF positivity was found to be a significant predictor of EULAR moderate/good response to RTX (OR 7.5, $95 \%$ CI $2.216,25.380)^{21}$. RF-positive patients also showed superior EULAR response to RTX compared to RF-negative patients in a recent retrospective observational study $^{12}$. Our results agree with those studies; however, RF positivity was only associated with a decrease in DAS28, but not in achieving EULAR response. Presence of other autoantibodies may affect the results of this analysis, and lack of data on anticitrullinated protein antibodies (ACPA) may limit the effectiveness of these findings, because some of the RF-negative patients may be ACPA-positive and hence responding. ACPA has been reported to be a significant predictor of EULAR good response ${ }^{20}$.

Higher baseline DAS28 was found to be a significant predictor of a reduction in DAS28 in cases of anti-TNF failure. Female sex and higher baseline HAQ score were significant predictors of nonresponse to RTX as measured by the decrease in disease activity. Previous results from the BSRBR identified high baseline HAQ as a significant predictor of EULAR nonresponse in patients with RA treated with anti-TNF therapies ${ }^{30}$, suggesting that patients with high HAQ score are more likely to have irreversible disease. Lower baseline HAQ was found to be significantly associated with achieving ACR response $\geq 50$ in 110 patients with RA treated with RTX; however, in the same study lower baseline HAQ was not associated with EULAR response criteria ${ }^{21}$.

Older patients, those with higher baseline HAQ, and patients for whom 3 anti-TNF agents had failed were less likely to achieve disease remission. Our model did not identify any positive predictors of remission. In general, the percentage of patients achieving remission was low (8.1\%). Achieving disease remission after only a single course of RTX is probably not expected.

One of the key strengths of our analysis is the broad inclusion criteria of the patients studied, irrespective of their anti-TNF history, RF status, comorbidities, and concurrent nbDMARD use. These results reflect the current use of RTX for the treatment of RA in clinical practice in the United Kingdom. Although RTX is licensed for patients who had failed at least 1 anti-TNF therapy, $16.4 \%$ of the patients were found to be anti-TNF-naive. This may be because those patients may have had a contraindication to anti-TNF therapies such as prior malignancy, presence of connective tissue disease, previous demyelination, previous joint sepsis, previ-

Personal non-commercial use only. The Journal of Rheumatology Copyright $@$ C 2012. All rights reserved. 
ous tuberculosis, or recurrent skin sepsis. Indeed, this may be why we found that anti-TNF-naive patients had more comorbidities than anti-TNF-failure patients. Interestingly, only $53.1 \%$ of all patients with RTX included in our analysis were receiving RTX in combination with MTX, as in the recommended license.

In line with most observational studies, missing data for some variables is a possible limitation of our analysis. However, the missing data in the variables included in the multivariate models did not exceed $10 \%$. Other possible limitations might be that the decision to start RTX was left to the treating physician, and only 1 reason was assigned at the time for stopping the previous anti-TNF drug; however, in clinical practice, for some patients, the discontinuation of a therapy may have been for more than 1 reason.

Six months after starting the therapy, a first course of RTX was an effective treatment in patients with RA treated in routine clinical practice. The response was similar in cases of anti-TNF failure and in patients who were anti-TNF-naive. High baseline DAS28 and RF-positive status were significantly associated with a decrease in DAS28, while women and patients with high baseline disability were less likely to respond to RTX.

\section{ACKNOWLEDGMENT}

The authors acknowledge the collaboration of all consultant rheumatologists and their specialist nurses in the United Kingdom, who provided the data. In addition, we acknowledge the support from Dr. Ian Griffiths (past chair) and Prof. David Isenberg (current chair) of the BSRBR Management Committee; Prof. Gabriel Panayi, Prof. David G.I. Scott, Dr. Andrew Bamji, Dr. Deborah Bax, and Dr. David L. Scott, presidents of the BSR during the period of data collection, for their active role in enabling the register to undertake its tasks, and to Samantha Peters (CEO of the BSR), Nia Taylor, Mervyn Hogg, and members of the BSRBR Scientific Steering Committee. We also acknowledge the seminal role of the BSR Clinical Affairs Committee for establishing national biologic guidelines and recommendations for such a register. Finally, we acknowledge the substantial contribution of Andy Tracey and Katie McGrother in database design and manipulation and Prof. Alan Silman in his prior role as a principal investigator of the BSRBR.

\section{REFERENCES}

1. European Medicines Evaluation Agency. EPARs for authorised medicinal products for human use. 2006 June 1. [Internet. Accessed Oct 18, 2011]. Available from:

http://www.ema.europa.eu/docs/en_GB/document_library/ EPAR_-_Assessment_Report_-_Variation/human/000165/ WC500025822.pdf

2. U.S. Food and Drug Administration. Approval letter for rituximab. Department of Health and Human Services. Feb 28, 2006. [Internet. Accessed Oct 18, 2011]. Available from: http://www.accessdata. fda.gov/drugsatfda_docs/appletter/2006/ 103705s5211_ltr.pdf

3. Cohen SB, Emery P, Greenwald MW, Dougados M, Furie RA, Genovese MC, et al; REFLEX Trial Group. Rituximab for rheumatoid arthritis refractory to anti-tumor necrosis factor therapy: Results of a multicenter, randomized, double-blind, placebo-controlled, phase III trial evaluating primary efficacy and safety at twenty-four weeks. Arthritis Rheum 2006;54:2793-806.

4. Edwards JC, Szczepanski L, Szechinski J, Filipowicz-Sosnowska A, Emery P, Close DR, et al. Efficacy of B-cell-targeted therapy with rituximab in patients with rheumatoid arthritis. N Engl J Med
2004;350:2572-81.

5. Emery P, Fleischmann R, Filipowicz-Sosnowska A, Schechtman J, Szczepanski L, Kavanaugh A, et al: the DANCER Study Group. The efficacy and safety of rituximab in patients with active rheumatoid arthritis despite methotrexate treatment: Results of a phase IIB randomized, double-blind, placebo-controlled, dose-ranging trial. Arthritis Rheum 2006;54:1390-400.

6. Emery P, Deodhar A, Rigby WF, Isaacs JD, Combe B, Racewicz AJ, et al. Efficacy and safety of different doses and retreatment of rituximab: A randomised, placebo-controlled trial in patients who are biological naive with active rheumatoid arthritis and an inadequate response to methotrexate (Study Evaluating Rituximab's Efficacy in MTX iNadequate rEsponders (SERENE)). Ann Rheum Dis 2010;69:1629-35.

7. Rubbert-Roth A, Tak PP, Zerbini C, Tremblay JL, Carreno L, Armstrong G, et al. Efficacy and safety of various repeat treatment dosing regimens of rituximab in patients with active rheumatoid arthritis: Results of a Phase III randomized study (MIRROR). Rheumatology 2010;49:1683-93.

8. Mease PJ, Cohen S, Gaylis NB, Chubick A, Kaell AT, Greenwald $M$, et al. Efficacy and safety of retreatment in patients with rheumatoid arthritis with previous inadequate response to tumor necrosis factor inhibitors: Results from the SUNRISE trial. J Rheumatol 2010;37:917-27.

9. Tak PP, Rigby WF, Rubbert-Roth A, Peterfy CG, van Vollenhoven $\mathrm{RF}$, Stohl W, et al. Inhibition of joint damage and improved clinical outcomes with rituximab plus methotrexate in early active rheumatoid arthritis: The IMAGE trial. Ann Rheum Dis 2011;70:39-46.

10. McGonagle D, Tan AL, Madden J, Taylor L, Emery P. Rituximab use in everyday clinical practice as a first-line biologic therapy for the treatment of DMARD-resistant rheumatoid arthritis. Rheumatology 2008;47:865-7.

11. Vital EM, Dass S, Rawstron AC, Buch MH, Goeb V, Henshaw K, et al. Management of nonresponse to rituximab in rheumatoid arthritis: predictors and outcome of re-treatment. Arthritis Rheum 2010;62:1273-9.

12. Solau-Gervais E, Prudhomme C, Philippe P, Duhamel A, Dupont-Creteur C, Legrand JL, et al. Efficacy of rituximab in the treatment of rheumatoid arthritis. Influence of serologic status, coprescription of methotrexate and prior TNF-alpha inhibitors exposure. Joint Bone Spine 2011 July 1 [E-pub ahead of print].

13. Bokarewa M, Lindholm C, Zendjanchi K, Nadali M, Tarkowski A. Efficacy of anti-CD20 treatment in patients with rheumatoid arthritis resistant to a combination of methotrexate/anti-TNF therapy. Scand J Immunol 2007;66:476-83.

14. Finckh A, Ciurea A, Brulhart L, Kyburz D, Moller B, Dehler S, et al. B cell depletion may be more effective than switching to an alternative anti-tumor necrosis factor agent in rheumatoid arthritis patients with inadequate response to anti-tumor necrosis factor agents. Arthritis Rheum 2007;56:1417-23.

15. Jois RN, Masding A, Somerville M, Gaffney K, Scott DG. Rituximab therapy in patients with resistant rheumatoid arthritis: Real-life experience. Rheumatology 2007;46:980-2.

16. Assous N, Gossec L, Dougados M, Kahan A, Allanore Y. Efficacy of rituximab in patients with rheumatoid arthritis refractory or with contra-indication to anti-tumor necrosis factor-alpha drugs in daily practice: An open label observational study. Clin Exp Rheumatol 2007;25:504.

17. Valleala H, Korpela M, Mottonen T, Hienonen-Kempas T, Kauppi M, Hannonen P, et al. Rituximab therapy in patients with rheumatoid arthritis refractory or with contraindication to anti-tumour necrosis factor drugs: Real-life experience in Finnish patients. Scand J Rheumatol 2009;38:323-7.

18. Yin HL, Chiu MC, Hung TC, Mak A, Yuk CM, Lung YK.

Personal non-commercial use only. The Journal of Rheumatology Copyright $@$ C 2012. All rights reserved. 
Rituximab for refractory rheumatoid arthritis: A 24-week open-label prospective study. Open Rheumatol J 2007;1:1-4.

19. Owczarczyk K, Hellmann M, Fliedner G, Rohrs T, Maizus K, Passon D, et al. Clinical outcome and B cell depletion in patients with rheumatoid arthritis receiving rituximab monotherapy in comparison with patients receiving concomitant methotrexate. Ann Rheum Dis 2008;67:1648-9.

20. Chatzidionysiou K, Lie E, Nasonov E, Lukina G, Hetland ML, Tarp $\mathrm{U}$, et al. Highest clinical effectiveness of rituximab in autoantibody-positive patients with rheumatoid arthritis and in those for whom no more than one previous TNF antagonist has failed: Pooled data from 10 European registries. Ann Rheum Dis 2011;70:1575-80.

21. Quartuccio L, Fabris M, Salvin S, Atzeni F, Saracco M, Benucci M, et al. Rheumatoid factor positivity rather than anti-CCP positivity, a lower disability and a lower number of anti-TNF agents failed are associated with response to rituximab in rheumatoid arthritis. Rheumatology 2009;48:1557-9.

22. Silman A, Symmons D, Scott DG, Griffiths I. British Society for Rheumatology Biologics Register. Ann Rheum Dis 2003;62 Suppl 2:ii28-9.

23. The EuroQol Group. EuroQol - a new facility for the measurement of health-related quality of life. Health Policy 1990;16:199-208.
24. Bruce B, Fries JF. The Health Assessment Questionnaire (HAQ). Clin Exp Rheumatol 2005;23:S14-8.

25. Prevoo ML, van 't Hof MA, Kuper HH, van Leeuwen MA, van de Putte LB, van Riel PL. Modified disease activity scores that include twenty-eight-joint counts. Development and validation in a prospective longitudinal study of patients with rheumatoid arthritis. Arthritis Rheum 1995;38:44-8.

26. van Gestel AM, Haagsma CJ, van Riel PL. Validation of rheumatoid arthritis improvement criteria that include simplified joint counts. Arthritis Rheum 1998;41:1845-50.

27. Fransen J, Creemers MC, van Riel PL. Remission in rheumatoid arthritis: agreement of the disease activity score (DAS28) with the ARA preliminary remission criteria. Rheumatology 2004;43:1252-5.

28. Sato T, Matsuyama Y. Marginal structural models as a tool for standardization. Epidemiology 2003;14:680-6.

29. Strand V, Balbir-Gurman A, Pavelka K, Emery P, Li N, Yin M, et al. Sustained benefit in rheumatoid arthritis following one course of rituximab: improvements in physical function over 2 years. Rheumatology 2006;45:1505-13.

30. Hyrich KL, Watson KD, Silman AJ, Symmons DP. Predictors of response to anti-TNF-alpha therapy among patients with rheumatoid arthritis: Results from the British Society for Rheumatology Biologics Register. Rheumatology 2006;45:1558-65. 